17.1

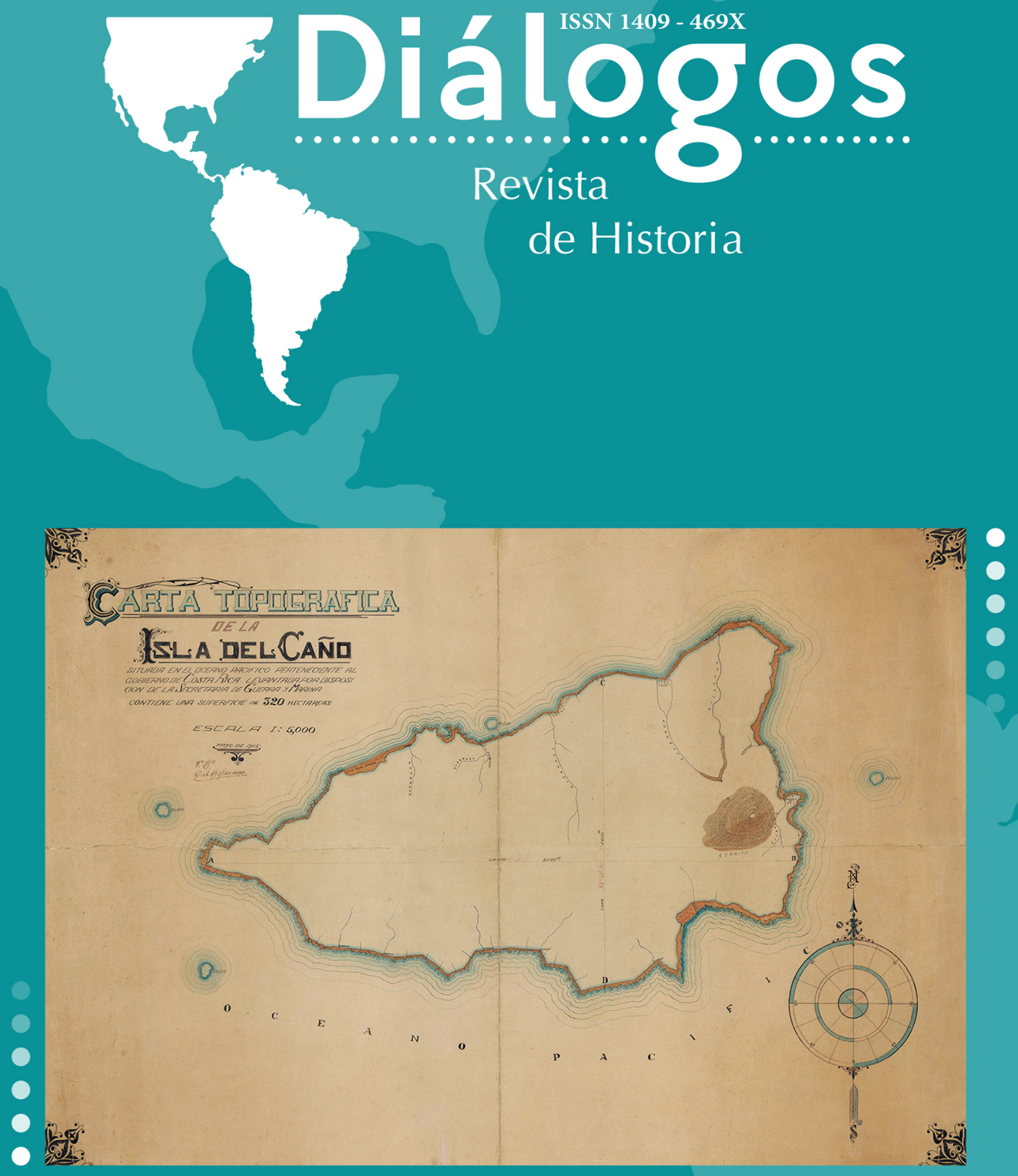

Escuela de Historia. Universidad de Costa Rica

Enero-junio 2016

url: http://revistas.ucr.ac.cr/index.php/dialogos/index 


\title{
REPRESENTACIONES SOBRE LA INFANCIA \\ EN EL CARIBE COLOMBIANO. UN ESTUDIO A \\ PARTIR DEL ESPACIO ESCOLAR (1850-1898)
}

Luis Alarcón Meneses

Celmira Castro Suarez

\begin{abstract}
Resumen
En todo escenario escolar confluyen múltiples actores, quienes, desde sus intereses y representaciones particulares, juegan algunos roles que hacen parte integral de la llamada cultura escolar. Estos actores construyen, al interior y fuera de la escuela, espacios de sociabilidad propios del carácter relacional de los individuos, al mismo tiempo que permiten conocer aspectos importantes del funcionamiento y organización de la escuela. Por esta razón su estudio resulta importante en la medida en que enseña, desde la vida cotidiana, sus discursos, sus prácticas y representaciones, cuál ha sido el desarrollo de la escuela como objeto histórico.

Palabras claves: alumno, espacio escolar, práctica educativa, siglo XIX .

\section{REPRESENTATIONS ABOUT CHILDHOOD IN THE COLOMBIAN CARIBBEAN. A CASE STUDY FOCUSED ON THE EDUCATIVE SPACE (1850-1898)}

\begin{abstract}
In any school setting converge multiple actors, who, from their interests and representations play some roles that are an integral part of the school culture called. These actors construct, within and outside the school, places of sociability own relational character of individuals, while important aspects provide insight into the functioning and organization of the school. For this reason the study is important as it teaches from everyday life, discourses, practices and representations which has been the development of the school as a historical object.
\end{abstract}

Keywords: violence, social sciences, history, Colombia.

Fecha de recepción: 2 de julio de 2015 • Fecha de aceptación: 9 de setiembre de 2015

\footnotetext{
- Luis Alfonso Alarcón Meneses • Doctor en Historia de la Eduación (UNED), Profesor

- investigador T.C/Titular, Programa de Historia, Facultad de Ciencias Humanas,

- Universidad del Atlántico, Colombia.

- Celmira Castro Suarez • Docente Programa de Sociología e Integrante del Grupo Historia

- de la Educación e Identidad Nacional, Colombia.
} 


\section{PRESENTACIÓN}

Los alumnos, conjuntamente con los maestros, constituyen uno de los principales actores del escenario educativo; son quienes desde sus roles terminaron generando las particularidades que la cultura escolar alcanzó en las escuelas que funcionaron en el Caribe colombiano durante la segunda mitad del siglo XIX. Por ello historiarlos permite conocer las dinámicas del proceso educativo y al mismo tiempo ocuparnos de estos actores educativos nos transporta, al interior del espacio escolar; es decir, más allá del discurso pedagógico y de la retórica de administradores y supervisores que muchas veces observaban las instituciones escolares desde afuera, sin entrar en detalles sobre las prácticas educativas que allí tenían lugar. ${ }^{1}$

El alumno, como actor del escenario educativo-escolar estaba estrechamente ligado a la imagen del niño, al cual para la época se le reconocía como un sujeto con identidad propia y no como un hombre en miniatura, tal como se le había considerado desde tiempo atrás en el mundo occidental (Ariès, P., 1987, p. 38; Escolano, 2000, pp. 25-39); una persona a la cual era necesario educar con el propósito de convertirla en un futuro hombre de bien, capaz de actuar con hábitos de urbanidad y buenas costumbres en la sociedad en la que vivía, tal como lo planteaba la normatividad educativa expedida en Colombia durante la segunda mitad del siglo XIX.

Con respecto al alumno como actor del escenario educativo, este artículo analiza: ¿Qué tipo de condiciones sociales debió enfrentar la infancia en la región? ¿Cuál fue el imaginario en torno a la infancia como sujeto por disciplinar y educar? ¿Qué porcentaje de asistencia escolar se dio en la región? ¿Cuál fue el discurso sobre los métodos pedagógicos utilizados para educar la infancia?

\section{LA FORMACIÓN DE LA INFANCIA COMO SUJETO EDUCATIVO}

Quienes concurrían a la escuela en calidad de alumnos constituyeron uno de los actores más importantes del escenario escolar que tuvo lugar durante la segunda mitad del siglo XIX. Fueron el centro de la mayor parte de las políticas educativas del régimen federal y, al mismo tiempo, factor de discordia con los poderes político y religioso opuestos a la educación laica que se pretendió impartir en los espacios educativos y la cual también encontró, en el peso de la tradición cultural y las condiciones económicas de una sociedad fundamentalmente campesina, un obstáculo para lograr la asistencia regular de los niños a las escuelas. Los espacios educativos, según el Decreto Orgánico de Instrucción Pública (1870, p. 11), tenían como objeto formar hombres sanos de cuerpo y de espíritu, dignos y capaces de ser ciudadanos y magistrados de una sociedad republicana y libre, razón por la cual se les ordenaba a los maestros instruirlos en los derechos y deberes que tenían como colombianos, tanto en su condición de ciudadanos como en el ejercicio de funciones públicas. 
El alumno, como actor del escenario educativo-escolar, estaba estrechamente ligado a la imagen del niño, el cual para la época era reconocido como un sujeto con identidad propia y no como un hombre en miniatura, tal como se le había considerado desde tiempo atrás en el mundo occidental (Ariès, 1987, p. 38; Escolano, 2000, pp. 25-39); una persona a la cual era necesario educar con el propósito de convertirla en un futuro hombre de bien, capaz de actuar con hábitos de urbanidad y buenas costumbres en la sociedad en la que vivía, tal como lo planteaba la normatividad educativa expedida en Colombia durante la segunda mitad del siglo XIX.

Efectivamente, el Reglamento de Instrucción Primaria del Estado de Bolívar, en correspondencia con las ideas pedagógicas de la época, consideraba que los niños solo se debían admitir en las escuelas del Estado una vez cumplieran los 6 años, edad considerada como apropiada para iniciar su formación primaria, en la cual permanecerían hasta los 12 años cuando debían pasar a la escuela superior, en la que continuaban hasta cumplir los 18. En tal sentido, la condición de alumno estaba directamente relacionada con la infancia y la adolescencia siguiendo así los fundamentos pedagógicos de Fröebel (1885, pp. 34-80), entre otros, quien consideraba que durante el segundo grado de desarrollo del hombre, es decir, durante la niñez, la escuela debía continuar la educación iniciada por la familia:

Que los niños entren a la escuela elemental a los seis años de edad, con la simple educación recibida en el hogar o en el Jardín de infancia; hagan sus cursos elementales en seis años, y pasen entonces a la escuela primaria, en otros seis años: pero mientras se obtiene dicho completo arreglo y se establecen las mencionadas costumbres, en los distritos en donde no haya escuela superior y la haya elemental, se podrán admitir en esta niños hasta de 10 años de edad y continuar su educación hasta los 14. (Reglamento de la Instrucción Pública Primaria en el Estado de Bolívar, 1886, p. 34).

En términos generales, la legislación educativa del período consideró la escuela como el complemento ideal para la educación que el niño debía iniciar en el seno de la familia, con lo cual se estaba en correspondencia, por lo menos en teoría, con las tendencias pedagógicas desarrolladas en el mundo occidental. Tales corrientes consideraban la existencia de una estrecha relación entre niño, adolescente y alumno, en la medida en que la condición de los primeros los convertía en potenciales candidatos para vincularse como alumnos al sistema escolar estatal.

Como lo afirma Naradowski (1994) en su estudio sobre la infancia, para el siglo XIX la pedagogía y la sociedad en general reconocían la correspondencia existencial entre el niño y el alumno quienes, para los responsables del sistema escolar, eran considerados un mismo ser, sin importar si desde el punto de vista epistemológico constituyen objetos diferentes. En efecto, según este autor, "aunque el alumno está en algún grado incluido en el niño, sobre todo en el ámbito delimitado por la edad, tampoco es menos cierto que el alumno en tanto objeto de conocimiento contiene caracteres que sobrepasan al niño en general" (1994, p. 26). En tal sentido, el alumno hay que entenderlo como un campo de intervención no distante a la niñez 
sino más complejo, por lo cual es necesario transcender la perspectiva pedagógica $\mathrm{y}$ adentrarse en las otras facetas que este actor del escenario social y educativo ha desarrollado en un tiempo y espacio determinado. ${ }^{2}$

Ello implica que al ocuparnos del alumno que acudía a las escuelas durante el periodo federal, simultáneamente hagamos referencia al niño y en particular a las características de la infancia existente en la región para la época, la cual no puede ser considerada como un hecho dado y un supuesto indiscutible a partir de la cual se formó el alumno. Tal como lo ha planteado Philip Ariès (1987) para el caso europeo, la infancia es una construcción histórica moderna que va más allá de un simple sujeto $^{3}$ preexistente en la sociedad sobre el cual interviene el Estado educador.

En el proceso histórico que dio lugar a la infancia, la escuela jugó un papel significativo en la medida en que esta se convirtió en un espacio de modelación de la niñez (Becchi, 2005, p. 35; Brehony, 2009, pp. 45, 585-604). Pero también era un instrumento para su vigilancia y control (Foucault, 1996, pp. 175-198). Por lo tanto, alumno, infancia y escuela se encontraban estrechamente relacionados (Padilla y Escalante, 2001, p. 115). Por esta razón, antes de ocuparnos del alumnado es relevante dar cuenta en este trabajo de la infancia a partir de la cual el niño cobraba vida (Pancera, 2005, pp. 21-38).

El mundo de la infancia del siglo XIX, así como del estudiante, ha sido escasamente analizado desde la perspectiva histórica en la región Caribe colombiana. Esto es de cierta manera el resultado del escaso interés en este tipo de temas por parte de la historiografía regional. Los pocos acercamientos a esta temática en Colombia se circunscriben fundamentalmente al llamado "país andino",4 dejando de lado otras regiones del país, por lo cual el saber histórico sobre el tema desde la perspectiva regional aún está por construirse.

\section{CON MUCHA DIFICULTAD SE LOGRA CRIAR A LOS NIÑOS POR ESTAS TIERRAS...}

Sin pretender llenar el vacío historiográfico sobre la infancia en la región, lo cual rebasaría las pretensiones iniciales de esta investigación, considero importante, para establecer el telón de fondo o el contexto socio-educativo referente al alumno como sujeto educativo, ocuparnos brevemente de las condiciones de la niñez en los pueblos, campos y ciudades de la región. Dicha intención fue el objeto central de un proyecto que consideraba que "educar a un niño era civilizar a un bárbaro".

Ocuparnos de las condiciones de la niñez en la región, supone inicialmente acercarnos a su cuantificación, es decir, a cuántos ascendían aproximadamente los niños en el territorio de las antiguas gobernaciones coloniales de Cartagena y Santa Marta. Ambas gobernaciones, luego del proceso de independencia, habían visto mermar una población mayoritariamente mestiza y la cual en su conjunto a mediados de los setenta, alcanzaba los 326704 habitantes, de los cuales la población infantil 
- de 1 a 7 años de edad - representaba cerca de los 80540 niños; es decir, el 25\%, porcentaje igual al del país, el cual entre 1835 y 1898 presentó en promedio unas tasas de natalidad y mortalidad cercanas al $56 \%$ y $40 \%$, respectivamente, con una tasa de crecimiento anual del 1,6\%. ${ }^{5}$ Sin embargo, para la región costeña, incluido el Estado de Panamá, solo sería del 1,2\% anual, muy por debajo de regiones como Antioquia la cual, para entonces, presentó un crecimiento poblacional anual del 2,18\% (Flórez y Romero, s.f.; Kalmanovitz y López, s.f.; Melo, 2014).

En cuanto a la mortalidad infantil a nivel nacional, esta era de 297 por 100 000 , con una tasa total de fecundidad alrededor de 8,5 hijos por mujer y con una expectativa de vida al nacer de 26 años (Kalamovitz y López, s.f.). En regiones como la costa Caribe, la mortalidad infantil era mucho mayor que el promedio nacional, lo cual se ve reflejado en su baja tasa de crecimiento poblacional: $1,2 \%$. De cierta manera, es un indicador de las malas condiciones nutricionales, salud, higiene y educación, lo cual sumado a las inundaciones causadas por las condiciones climáticas de "una inmensa llanura anegada" (Pérez, 1863, p. 14), terminaron generando un mayor número de fallecimientos en los niños nacidos vivos:

Todos ellos son, pues, muy pobres y desgraciados, porque de las diez plagas que azotaron a Egipto padecen cinco: la corrupción de las aguas, las úlceras, los reptiles, los moscones y la mortalidad infantil. En efecto, con mucha dificultad se logra criar a los niños. (Mollien, 2004).

En efecto, las condiciones tropicales generaban en algunas zonas de la región un clima tan adverso que, al decir de algunos viajeros y geógrafos de la época, "parecía impedir a veces las posibilidades de la misma existencia humana en el territorio costeño" (Posada, 1993, p. 93). Periodos de extremo calor al cual le seguían meses de lluvias e inundaciones que producían enfermedades como la fiebre amarilla, el cólera morbo y el dengue - (conocido entonces como la peste del trapiche) transmitido por "zancudos y jejenes que no dejan vivir" (Posada, 1993, p. 93) - eran el azote de la población apostada a las orillas de ciénagas y ríos, tal como lo anotó el viajero francés Luis Striffler, para quien "los insectos viajeros ávidos de sangre, se multiplicaban a tal punto, que ni de día ni de noche había descanso afuera de los toldos" (Posada, 1993, pp. 93-94). Las inundaciones también arrasaban con cosechas y animales, produciendo hambre en familias enteras, las cuales, además de perder los pocos enseres con que contaban en sus casas y ranchos, permanecían expuestas a la insalubridad de las aguas estancadas, condición que afectaba especialmente a la población infantil.

Otro factor de mortalidad infantil eran las pésimas condiciones higiénicas en cuanto al parto y la falta de cuidados prenatales. Ello generaba que muy pocos niños sobrevivieran al nacimiento e incluso, muchas madres morían también al momento de dar a luz. Porque en el mejor de los casos eran asistidas en sus mismas casas por parteras y curanderas, siendo casi inexistente la presencia de médicos, incluso en las familias de mejor condición social: 
Acaeció una noche de septiembre, en que se presentó una tempestad, mucha lluvia, truenos y relámpagos, el nacimiento prematuro de una niña, sin comadre ni comadrón; la divina providencia la favoreció, no tuvieron la menor gravedad ni la madre ni la hija... Al otro año de 1870, nació y murió mi tercer hermano, nombrado Carlos; su brevísima vida hace pensar en los versos de Rioja, La Rosa, en que al contemplar una gota de rocío la aurora no sabe si su nacimiento o muerte llora. (Revollo, 1998, pp. 7, 40).

Quienes sobrevivían a su nacimiento se criaban en condiciones desfavorables. Incluso, en los pueblos y haciendas algunas familias, ya fuera por carecer de camas o por costumbre ancestral, al momento de dormir durante la noche hacinaban a sus niños, inclusive bebés recién nacidos, en el suelo de tierra de sus ranchos, el cual en época de invierno concentraba más humedad que de costumbre. Por lo general, ello propiciaba la aparición de enfermedades entre la población infantil, la cual dormía en el suelo mientras los adultos lo hacían en las pocas camas o hamacas existentes en la casa:

\begin{abstract}
Los niños duermen en esteras en el suelo, envueltos en una cobija como en un capullo. Clementina, la niña mayor, duerme con el bebé acurrucado maternalmente en los brazos. Todos los niños se desnudan completamente antes de envolverse en la cobija; tuve el atrevimiento de preguntarles si las señoritas hacen lo mismo y ellos me dijeron que sí. (Holton, 1857/1981, p. 446).
\end{abstract}

Tanto en ciudades como en pueblos y zonas rurales los niños de los sectores populares, quienes por lo general eran producto de uniones de hecho o ilegítimas, como se les consideraba entonces, andaban desnudos no solo en sus casas sino también en las calles, plazas de mercado y otros lugares públicos. Esto denota, además de las penurias económicas, ciertas prácticas culturales en las cuales había poca atención hacia los niños por parte de los adultos, como lo dejan ver los cuadros de costumbres y dibujos realizados por viajeros o cronistas locales. Por lo general, lo muestran desprovisto de ropas y calzado tal como lo describió al llegar al puerto de Sabanilla el inglés Isaac Holton (1857/1981):

La primera casa a la que entré constaba de un cuarto grande, casi vacío, y era quizá la casa de un empleado de la aduana. En el suelo vi algo que a primera vista me pareció un mico grande, pero que al mirarlo mejor y para mi desconcierto resultó ser un niño desnudo y del color de la tierra donde estaba gateando. En otra casa vi otro espécimen similar, encima de un cuero y meciéndose en una hamaca. (p. 31).

Por su parte, el viajero sueco Carl Gosselman(1981) sobre el particular describía:

La mayoría de las calles no están empedradas sino llenas de arena, y en distintos lugares pueden verse grupos de negritos desnudos dando volteretas, muchas veces en compañía de un mico, el que solamente se distingue de ellos por sus saltos más altos y sus movimientos más ágiles. (p. 43).

Incluso en ciudades como Barranquilla, Santa Marta y Cartagena los niños andaban desnudos en las calles y plazas de mercado, correteando detrás de los 
animales o al lado de algún adulto, tal como se observa en los siguientes grabados de la época, en los cuales los niños aparecen sin ropa.

La falta de vestuario para los niños, además de ser una muestra de la pobreza de la mayoría de la población de la región, era una de las razones que los padres aducían para no enviar sus hijos a la escuela. Ciertamente, la pobreza imperante en la mayoría de las poblaciones de los Estados de Bolívar y Magdalena era tal que los padres no contaban con los medios para vestir y calzar a sus hijos para enviarlos a la escuela. Esta situación que se convirtió en una de las razones que se esgrimían en los informes de asistencia:

No asiste por no tener vestido... no asistió por no contar sus padres con los medios para comprarle calzado... se opone la gran miseria del pueblo por qué bien se hallan ocupados en las necesidades domésticas, o bien desnudos, descalzos o escasísimos: cosas que provienen de aquella situación y que interceptan el curso ordinario de dicha asistencia a la escuela. (Archivo Histórico del Magdalena, 1871).

Esta circunstancia llevó a que en varias oportunidades los cabildos municipales aprobaran partidas para auxiliar a los padres para que les compraran ropa y calzado a sus hijos. Estos auxilios muchas veces se quedaban en las actas de papel, pues los distritos tampoco contaban con los medios para hacerlos efectivos: "El tesoro de los distritos está en estado de postración lamentable" (“Informe del señor”, 1877, p. 25).

La falta de recursos y la pobreza no fue una condición exclusiva de las familias de la región costeña, ya que en otras zonas como la andina la penuria también afectaba a un sector de la población, que se veía en aprietos para enviar a sus hijos a la escuela. Por ejemplo, en el mejor de los casos heredaban la ropa de su padre o hermanos mayores:

\begin{abstract}
Mi madre, que era viuda, anciana y muy pobre, habitaba una casuca situada en la calle de las Béjares; y como se desvivía por sacar de mí un hombre de provecho, apenas cumplí siete años, me puso en la escuela... El uniforme estudiantil consistía este en unos botines, que nunca conocieron la bola, y cuyas orejas, desatadas siempre, parecían las alas de un murciélago; unos calzones de manta, llenos de remiendos, y que dejaban asomar por lo menos una rodilla; una chaqueta, que, después de haber pertenecido a mi padre y a mi hermano mayor, que en paz descanse, había pasado a mi poder en terceras nupcias según la tradición. (Carrasquilla, 1866).
\end{abstract}

La pobreza que afligía a los sectores populares de la región afectó también a los niños en cuanto a su alimentación, la cual, en algunos casos, además de escasear como resultado de sequías, inundaciones o plagas, no era la apropiada para garantizar una buena nutrición y un desarrollo adecuado de los niños: "cuando la miseria y el hambre azotan a los desgraciados, que no encuentran ni un pan para los hijos que lloran" (“Informe del gobernador", 1881).

Los niños por lo general realizaban labores no remuneradas dentro de la estructura familiar, para apoyar con su mano de obra las labores de sus padres en 


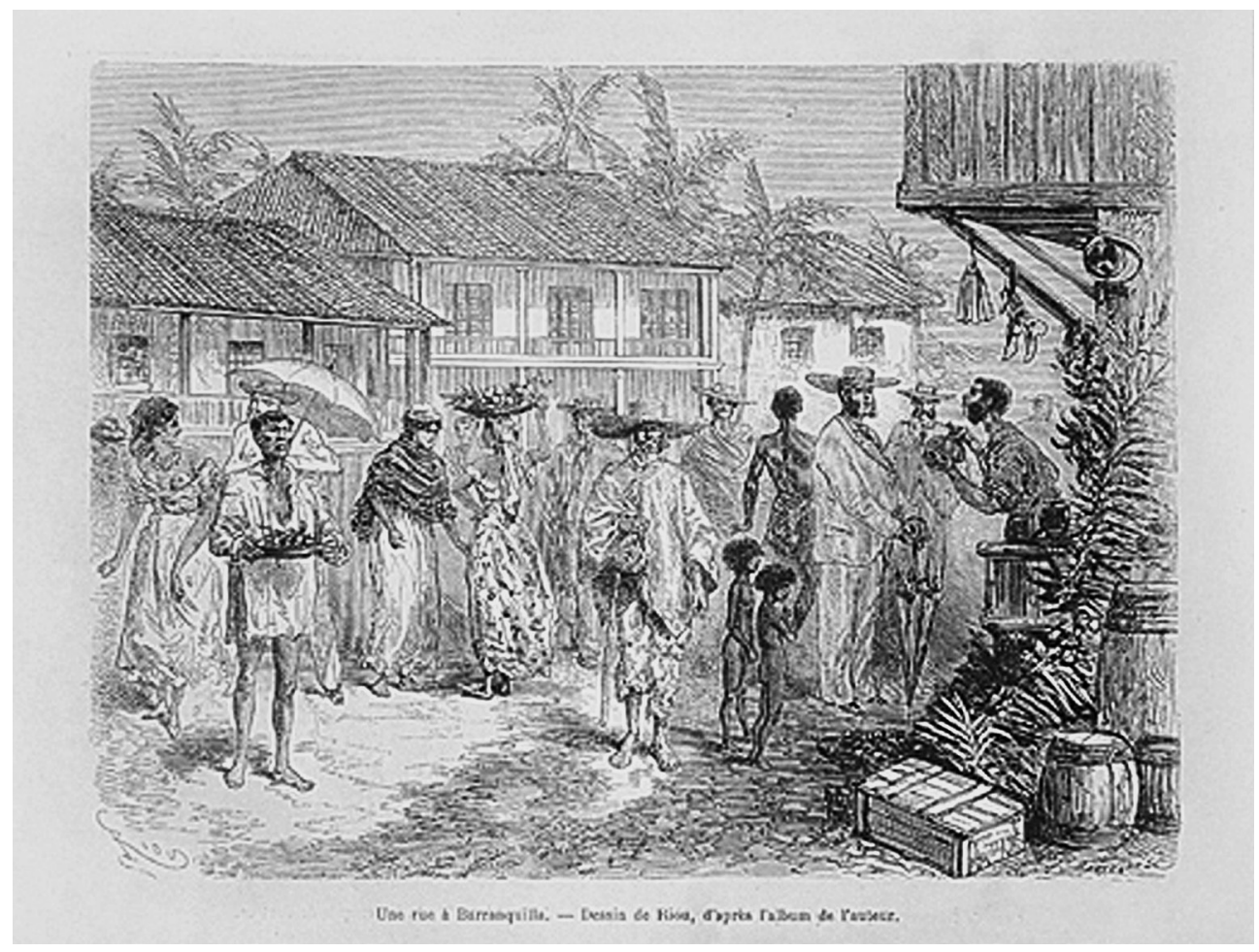

Figura 1. Una calle en Barranquilla (diseño de E. Riou, con base en un croquis del autor). Tomado de L'Amérique Équinoxiale (Colombie-Equateur-Perou), p. 12, por A. Édouard, 1869, Francia: Librería Hachette.

agricultura, ganadería, pesca, navegación, oficios domésticos o en el taller artesanal, actividades que a la postre les impedían asistir regularmente a la escuela.

En consecuencia, tal como lo ha estudiado el historiador Pablo Rodríguez (2004) para el caso de la familia colombiana, los niños en su mayoría no acudían a la escuela y se les incorporaba tempranamente a las actividades de los adultos. De esta manera:

Los hijos de campesinos y estancieros debían ayudar en distintas tareas. En época de cosecha recogían frutos, pastoreaban ganados, ordeñaban vacas, cargaban leña, limpiaban los surcos de malezas, perseguían langostas e insectos y espantaban torcazas. En las ciudades, los hijos de los artesanos colaboraban en las tareas de la casa y el taller. Como regla uno o varios hijos de un sastre, zapatero, herrero o carpintero por lo general seguían el oficio de su padre. (2004, p. 268).

El trabajo infantil, el cual constituía una práctica usual de cooperación y organización familiar - "a los varones los dedican los labriegos a las faenas de la agricultura desde los siete años" ("Informe anual”, 1870)—, además de ser un impedimento para que los niños asistieran a la escuela, se convirtió en una forma de adquirir algunos conocimientos necesarios para poder sobrevivir en una sociedad con muy pocas opciones laborales que ofrecer a sus habitantes. En este escenario, 
los niños debieron afrontar condiciones adversas para sobrevivir hasta alcanzar la mayoría de edad, que les permitiera convertirse en el ciudadano republicano anhelado por el régimen radical.

\section{REPRESENTACIONES SOBRE LA INFANCIA COMO SUJETO POR DISCIPLINAR Y EDUCAR}

El niño se convirtió en el centro del proyecto educativo del liberalismo radical. Por esta razón, su imagen ocupó un lugar importante en el discurso que sobre el particular circuló en el país y a través del cual se expuso la idea, al igual que en otros países latinoamericanos (Carli, 2002, p. 26), de que el niño era como un diamante en bruto que había que pulir; un ser al que había de moldeársele para convertirlo en un individuo civilizado y arrancarlo así de la barbarie en que estaba sumido desde su nacimiento. Desde entonces, tal como lo afirma Sandra Carli (2002) para el caso argentino, la infancia se convirtió en la destinataria principal de un discurso que la proyectaba como generación futura y como artífice de un nuevo orden a partir de la intervención político cultural de la educación.

El hecho de que el niño empezara a salir del anonimato y se le ubicara en un lugar importante dentro del discurso educativo, era el resultado de las preocupaciones que ya desde las primeras décadas del siglo XIX tenían las élites dirigentes con respecto a la necesidad de generalizar la instrucción pública primaria en la joven República. Esta situación de cierta manera contribuyó a construir una representación sobre la infancia en Colombia, que reprodujo y pretendió adecuar a la realidad del país los saberes existentes en la época sobre el niño, en especial sobre su naturaleza, así como de sus peculiaridades y atributos principales. En estas representaciones, el papel de la educación y del espacio escolar fue considerado como fundamental en el proceso de socializar al infante. Así, la escuela se convirtió en el

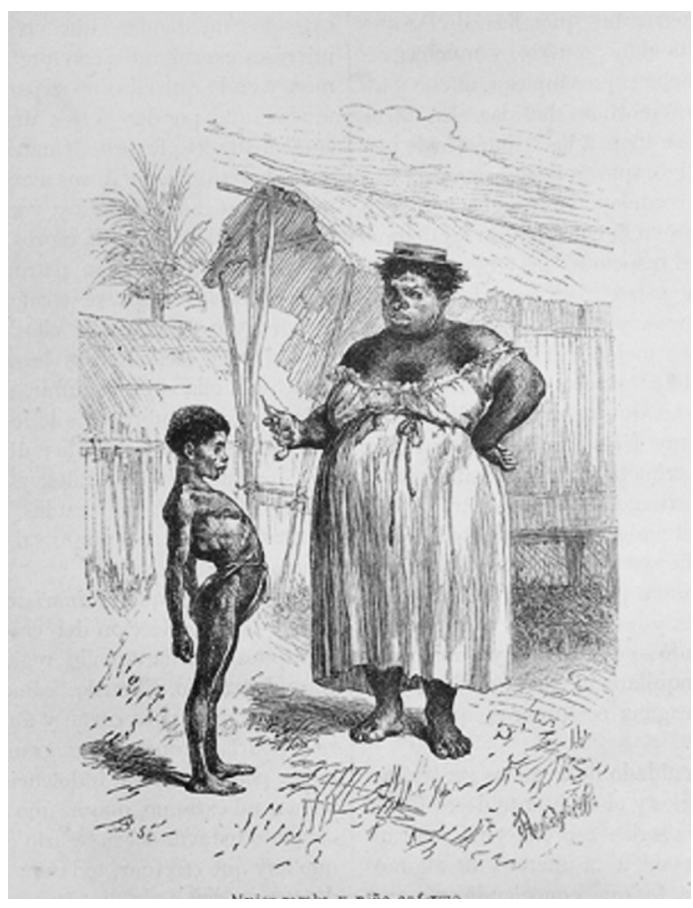

Figura 2. Mujer zamba y niño enfermo (grabado $12 \times 8 \mathrm{~cm}$, blanco y negro, por R. Armand). Tomado de Exploracones á los Istmos de Panamá y Darien en 1876, 1877 y 1878, p. 52, por R. Armand, 1881, España: Juan Vidal. 
lugar ideal para el aprendizaje de los nuevos valores de orden republicano a través de los cuales se buscó disciplinar al niño-alumno, al mismo tiempo que se pretendió, por lo menos en teoría, conocer su naturaleza y las particularidades propias de la realidad que le rodeaba:

Luego que el maestro reciba un niño, debe proponerse estudiarlo bien en las disposiciones comunes y propias de su situación y de su edad y en las individuales y constitutivas de las variedades de su espíritu y de sus caracteres. Para esto debe observar su temperamento y tener en cuenta todas las circunstancias que hayan podido influir en él relativas a su familia, relaciones, género de vida y conducta anterior. (Guarin, 1876, pp. 38-39).

Ello muestra cómo a la escuela también se le consideraba el principal núcleo de observación y construcción de saberes sobre este actor de la vida educativa, el cual también fue objeto de métodos de enseñanza que buscaban adecuarlo a los comportamientos, valores, creencias y conocimientos propios de una época positivista. A la infancia se le consideraba como un estadio social y biológico transitorio, tal como lo dejan entrever las publicaciones que al respecto circularon en el país:

La infancia, que comprende desde el nacimiento hasta la edad de seis y medio o siete años... La infancia es ese período en que la organización de la estructura física, por medio de la cual la mente obra sobre el mundo exterior, se halla incompleta; la niñez comienza cuando se perfecciona esta organización, y abraza ese tiempo en que los placeres puramente materiales son la preocupación de la vida; la juventud se manifiesta cuando las facultades intelectuales empiezan a interesarse en su propio ejercicio, y a adquirir solidez en sus actos, encontrando al institutor, por decirlo así, a la mitad del camino. (Periódico Oficial de la Instrucción Pública, 1872, p. 214).

La representación que sobre la infancia circulaba en el país a través fundamentalmente de la prensa educativa, consideraba que durante los primeros años de vida la familia debía ser el epicentro de la educación inicial del niño. Allí debería permanecer hasta que su cuerpo creciera físicamente y hasta que su mente y su carácter alcanzaran un mayor desarrollo y firmeza, para luego poderlo enviar a la escuela. Se consideraba que el deber del padre en esa época era eliminar todos los obstáculos que impidiesen el desarrollo espontáneo de sus facultades. Se insistía, además, en que al momento de desarrollarse el lenguaje en el niño, las palabras del padre debían acompañar y aclarar las impresiones que en él causara el entorno. Permanentemente se hacía énfasis en que la familia era el núcleo natural de la primera educación del niño, por lo cual el padre debía ser responsable de todas las influencias pertinentes antes de ser enviado a la escuela.

Ahora bien, no en todas las familias se podía llevar a cabo esta labor de educación inicial. En el mejor de los casos, solo se limitaban a brindar alimentación y algunos cuidados a unos niños que comúnmente, si algún día ingresaban a la escuela, llegaban a esta sin saber por lo menos de las letras y los números por medio de sus padres, quienes por lo general eran analfabetos: "En el distrito no hay ni siquiera el 
número necesario de padres de familia que sepan leer y escribir y quienes puedan enseñar las primeras letras a sus hijos" (Archivo Histórico del Magdalena, 1872).

En los pueblos de la costa, inclusive en las principales ciudades de esta región, muy pocas familias inculcaban adecuadamente la educación preliminar de sus hijos en casa. Algunas de estas familias afortunadas contaban con un padre o madre que, al saber leer y escribir, ejercían como los primeros maestros de sus hijos. Uno de estos niños privilegiados fue Pedro María Revollo (1998), quien años más tarde se convertiría en un importante personaje de la Iglesia católica en Barranquilla: "Aprendidos los Cristos y primeras letras en el hogar paterno, me pusieron en una escuela infantil, de esas que llaman ahora kindergarten" (p. 7).

El mismo Revollo (1998) cuenta cómo luego de aprender las primeras letras fue enviado a la escuela:

En ella iba yo a recibir clases y con mucho provecho; allí se dividían los alumnos, al uso antiguo los partidos romanos y cartaginés, en prusianos y franceses, por alusión a la recién pasada guerra franco-prusiana; unos llevaban al pecho una moña de cinta color rojo y los otros de otro color. Al fin del año se celebraron en la iglesia los exámenes vistosamente, me tocó ser examinado en geografía universal, a la corta edad de seis años con grande éxito. (p. 11).

En su descripción, Revollo, además de ilustrar sobre el funcionamiento de las escuelas, muestra algunos aspectos de la vida del alumno, a quien fundamentalmente la escuela pretendía alejar de los vicios e inculcarle buenas costumbres, así como los deberes y obligaciones ciudadanas que garantizaran la estabilidad y el orden social. Por esta razón el castigo, a pesar de estar proscrito por los nuevos métodos pedagógicos en boga, continuaba aplicándose "con el propósito de mantener la autoridad y el acatamiento hacia el maestro" (Archivo Histórico del Magdalena, 1877):

\footnotetext{
En medio de tantos bellos recuerdos, uno sin embargo conservo ingrato y hasta horrible: el sistema punitivo de la escuela que aplicaba mi padre, tributario de la época consistente en los azotes y la palmeta que no merecí nunca, pero que vi aplicar bárbaramente, sobre todo cuando los primeros eran a calzón bajo y cuerpo tendido. (Revollo, 1998, p. 12).
}

El castigo físico contra el alumno, a pesar de no estar considerado dentro del modelo de enseñanza objetiva vigente para la época, constituía una práctica tradicional que continuaba presente en las representaciones sobre la infancia y a la cual recurrían tanto maestros como padres de familia. Efectivamente, a pesar de que en los estados de Bolívar y Magdalena, como en el conjunto del país, los manuales de urbanidad y de enseñanza, así como otro tipo de publicaciones influenciadas por la pedagogía pestalozziana, criticaban y no consideraban el castigo físico como una práctica aceptable en las aulas, por ser un rezago del enfoque tradicional, este continuó aplicándose en algunas escuelas como una forma de "disciplinar el cuerpo y el alma" y así convertir al niño en miembro de una cultura y de una sociedad determinada (Carli, 2002, p. 26). 
Empero, a pesar de que en ciertos tratados de pedagogía y educación del periodo federal, al igual que en algunos escritos reproducidos por la prensa instruccionista se recomendaría la eliminación del castigo físico como pena ante la mala conducta de los alumnos, esta fue establecida y permitida por casi todas las reglamentaciones estatales de carácter educativo. En estas, se dejaba el castigo físico o "pena de dolor", así llamado en la época, como un recurso excepcional sin que ello implicara conducir hacia la barbarie y sin atentar contra el pudor o la salud del niño. Para ello se apoyaban en principios de pedagogos como Baldwin y Fitch, el primero consideraba que:

\begin{abstract}
Algunos alumnos suelen no ser sensibles a otras influencias que a las del padecimiento corporal. En casos extremos, y hasta que puedan utilizar otros recursos mejores, será necesario el empleo de esa fuerza. [Mientras que para Fitch], el castigo del cuerpo por ciertas faltas es el recurso disciplinario de la naturaleza. Bien mirado todo, no es el castigo físico lo que degrada, sino la culpa; de manera que si hay ciertas faltas que pueden ser curadas más prontamente por medio de estos castigos que por medio de otros recursos, los castigos corporales no necesitan mayor excusa. (Citados en Reglamento de la Instrucción Pública Primaria en el Estado de Bolívar, 1886, p. 55-60).
\end{abstract}

Estas ideas alimentaron la mentalidad tradicional y el imaginario sobre la infancia, pues a pesar de los cambios de orden social y político introducidos por los liberales radicales, continuaron imperando en la sociedad regional, la cual consentía esta forma de corregir a los niños y jóvenes que asistían a las escuelas, sobre quienes se ejercía el principio de vigilar y castigar (Foucault, 1996, p. 84).

En las representaciones que sobre la infancia y el alumno existían en la sociedad regional el castigo físico continuó estando presente como mecanismo de control y disciplina de la niñez. Por ello se prorrogó su aplicación en algunas escuelas, muy a pesar, tal como lo afirman algunos estudios sobre la infancia y la pedagogía en Colombia (Sáenz, Saldarriaga y Ospina, 1997, pp. 189-194), de que la implementación de modernos métodos como el de Pestalozzi permitieron realizar algunas modificaciones a los mecanismos de castigo. Sin embargo, mantuvieron su vigencia, muy a pesar de la llamada disciplina de confianza proclamada por la pedagogía activa e impulsada en el país por los liberales:

\footnotetext{
Los castigos dolorosos proscritos de la educación eminentemente filosófica preconizada en los pueblos más avanzados en civilización, se han continuado aplicando en la mayor parte de nuestras Escuelas, por lo mismo que aquel sistema no se observa si no en muy pocos Establecimientos del Estado según he observado más arriba, y no obstante la prohibición contenida en las disposiciones que rigen sobre la instrucción pública de algunos años a esta parte. ("Informe del director", 1878).
}

La práctica permanente del castigo físico en la escuela decimonónica implica un abordaje crítico de este fenómeno. Para ello se debe partir de su reconocimiento como una construcción histórica perteneciente a un tiempo y a un espacio en particular y en los cuales existen ciertos códigos culturales y representaciones sociales que 
legitiman o rechazan esta práctica, que no puede ser vista bajo ópticas maniqueas y moralistas que pretendan descalificarlas desde el presente.

Ciertamente, tal como lo afirman Obregón y Saldarriaga (1997), el castigo al alumno:

\begin{abstract}
Antes de ser un acto salvaje de violencia, de venganza individual, o incluso de represión institucional, el castigo escolar se encuentra ligado de modo indisoluble con los fines sociales asignados al hecho de mantener agrupados de modo regular unos niños fuera de su hogar: está vinculado con los fines morales de las prácticas religiosas, y con los fines político-económicos como la formación de hábitos de obediencia, disciplina y trabajo. Pues en la sociedad moderna no se permite golpear, humillar o encerrar a ninguno de sus miembros sin una razón filosófica o moral que lo justifique, y sin una técnica que lo haga efectivo y a la vez impersonal. La paradoja de la pedagogía es haber sido encargada de corregir y encauzar la naturaleza humana infantil, según el propósito de la sociedad moderna: formar sujetos libres pero responsables, es decir, autogobernados y autónomos. (p. 193).
\end{abstract}

Justificándose en la búsqueda y cumplimiento de este objetivo se estableció en la reglamentación escolar de la región un sistema de castigo y premiación, del cual el mismo Luis A Robles, director de Instrucción Pública del Magdalena en 1873, afirmaba:

Es innegable que los hombres se mueven a impulsos del placer y de la pena,
y que todo el que quiera dirigirlos en algún sentido; tiene que acudir a alguno
de estos ajustes impulsivos; pero como no es posible que nuestro gobierno,
ni ningún otro, adjudique un premio por cada acción ejecutada en cumpli-
miento de su deber se hace necesario ciertos caracteres para que sean eficaces.
("Informe del director", 1873, p. 95 ).

Para ampliar estos preceptos, Robles introdujo tres clases de premios en el reglamento de instrucción pública del Estado: conducta o moralidad, aprovechamiento y puntualidad, al mismo tiempo que se establecieron dentro del sistema de penas la amonestación privada, la amonestación en público y la represión con apercibimiento, las cuales eran aplicadas a las faltas menos graves; seguían el aislamiento de pie y separado de los demás, arresto con abstinencia y expulsión, para castigar faltas consideradas graves y gravísimas, antes de lo cual era necesario consultar y contar con la aprobación de la junta de vigilancia y del consejo departamental. En este reglamento general no se considera el castigo físico o "pena de dolor", lo cual no significa que no se aplicara en las escuelas del Estado, pues de hecho en los reglamentos de carácter local, así como en la práctica escolar continuaba aplicándose el uso de la férula para reprender a los niños y encausarlos en el orden y la disciplina escolar (Leyes y Decretos del Estado del Magdalena, 1879, p. 32).

El sistema correccional basado en premios y castigos se aplicó también en el Estado de Bolívar que, por hacer parte de la misma región Caribe, compartió con el Magdalena muchas identidades culturales y prácticas educativas. Razón por la cual aproximarnos a la legislación sobre el particular, nos acerca a los imaginarios y, por 
tanto, a los usos e importancia que en toda la región se le dio a esta forma de disciplinar al niño y civilizar al bárbaro.

\begin{abstract}
Al respecto, la legislación del Estado de Bolívar estableció:
El sistema correccional tiene por objeto destruir los defectos de carácter en los niños, evitar que comentan faltas, castigar las que cometan; habituarlos, en fin, al estricto cumplimiento de sus deberes; y como el temor de la pena y la esperanza de la recompensa son los dos grandes resortes del alma humana, el sistema correccional se compone de dos elementos: el premio y el castigo. (Reglamento de la Instrucción Pública Primaria del Estado de Bolívar, 1886, p. 54).
\end{abstract}

De acuerdo con estas consideraciones, en el Reglamento de la Instrucción Pública Primaria del Estado de Bolívar (1886) se establecieron una serie de premios similares a los existentes en el Estado del Magdalena y en otros estados de la Unión, pero se insistía en el hecho de limitar su otorgamiento, pues se partía de la premisa de que era mejor que el niño se acostumbrara a cumplir su deber sin esperar recompensa inmediata. Se inducía "a hacer el bien sólo porque es bien y a evitar el mal sólo porque es mal". También se le recomendaba al maestro que fuera parco en las alabanzas o aplausos, pues no se consideraba bueno que el alumno se acostumbrase a ellos por cualquier acción realizada. Se insistía en la prudencia de los maestros para otorgar los premios, por ello se les recomendaba no dejarse llevar por su benevolencia y aplicar un carácter viril y recto ante sus alumnos, evitando así premiarlos por "su mera inteligencia natural, sino más bien por aquella que fuese producto de su laboriosidad paciente", lo cual significaba que se premiaba más por la llamada conducta, aplicación y obediencia, que por las capacidades y desarrollo intelectual del niño.

Sin embargo, al ocuparse de los castigos la norma es más severa y por tanto más diligente en su aplicación. Se insistía entonces en que toda falta debía ser castigada según su gravedad, "se debe castigar las pequeñas, para no dar lugar a las grandes, pues la eficacia del castigo no consiste tanto en su gravedad como en su certeza" (Reglamento de la Instrucción Pública Primaria del Estado de Bolívar, 1886, p. 54). De acuerdo con esto, se recomendaba al maestro que el castigo debía ser inmediato: "debe seguir a la falta como la sombra al cuerpo" y evitar así la aplicación tardía de las penas, ya que perdían su total eficacia. Para que ello no ocurriera, se recomendaba al maestro tener completo dominio de sí mismo e imponer su carácter ante los alumnos: "su rostro debe expresar la grave indignación por las faltas", se decía. Lo anterior significaba imponerse como autoridad y reconocerle como el personaje que tenía la legitimidad, ante sus padres y la sociedad, para imponer penas o castigos, dentro de los cuales eran posibles tanto los de orden corporal como los de dolor físico.

Con respecto a las penas de dolor, se dispuso que estas estaban reservadas solo para las faltas que fueran "moralmente degradantes", lo cual era muy confuso, pues permitía a los maestros y directores imponerlas por distintas razones que iban desde las llamadas conductas antihigiénicas hasta no obedecer las órdenes del maestro, pasando por las denominadas faltas contra el pudor. Sin embargo, por algunas denuncias y 
quejas de padres de familia y alumnos, sabemos que estas penas de dolor - el uso de la férula o la posición de rodillas sobre un suelo lleno de granos de maíz-eran las más comunes. Muchas veces se aplicaban a los alumnos por la llamada falta de inteligencia y por incumplimiento de tareas (Archivo Histórico del Magdalena, 1884).

Se les recomendaba a los maestros no desesperarse si no veían "mejoría en la conducta de los niños", pues ello sería sinónimo de poca habilidad pedagógica. Es decir, no deberían jamás declararse incompetentes para corregir a un niño y debían tratar por todos los medios, pues se partía del criterio de que la educación era obra de paciencia, de mucha prudencia y discreción. El reglamento afirmaba que cuando se haya recorrido inútilmente:

Toda la escala de castigos aplicables al estado y defectos de un niño, vuélvase a principiar combinando los castigos con todos los recursos que sugieran el deseo de hacer el bien y la práctica; búsquese la causa de él y trátese de remediarlas, apelándose a la conciencia del alumno y a la de los demás. (Archivo Histórico del Magdalena, 1884).

De paciencia era que carecían muchos maestros y directores, quienes en la práctica recurrían a la expulsión como mecanismo para librarse de quienes ellos consideraban un individuo que daba mal ejemplo en la escuela.

La expulsión, al igual que otros tipos de castigos y reprimendas, incluso de tipo corporal, continuó haciendo parte del imaginario en torno a la infancia, sujeto al cual se le pretendía disciplinar con el propósito de lograr su formación ciudadana y evitar los actos de indisciplina.

Por otro lado, la indisciplina escolar pretendió controlarse a través de la imposición de una serie de mecanismos que fueron incorporados a disposiciones legales como el Decreto Orgánico de Instrucción Pública y reglamentos de carácter estatal y escolar, los cuales establecían los procedimientos que debían aplicarse de acuerdo con el tipo de falta cometida (comportamiento o aprovechamiento) por los alumnos. Estos actores eran recriminados y reprendidos severamente por el sistema de instrucción pública, a pesar de que este, orientado por la enseñanza objetiva, criticaba los castigos físicos que eran una práctica de los llamados métodos tradicionales que aún se aplicaban. Por tal razón, los alumnos en el país se referían a la escuela como el "lugar de mi suplicio" (Carrasquilla, 1866, p. 10):

\footnotetext{
Al terminar la escritura, don Fructuoso recostaba su silla de brazos en la puerta de la sala, y nosotros íbamos desfilando por delante de él, con la plana en la mano. Aquí era donde hacía uso de su formidable uña; pues cogiendo con ella y con la punta del dedo índice el párpado del que no había escrito a su gusto, se lo retorcía de una manera espantosa, haciéndole ver estrellas y dejándolo tuerto por todo el tiempo que el párpado tardaba en volver a su acostumbrado lugar. (Carrasquilla, 1866, p. 10).
}

Se trataba, como lo han planteado algunos pensadores modernos e historiadores de la educación, de vigilar y castigar al niño (Foucault, 1996), principio del cual es 
portadora la legislación y la reglamentación escolar, tanto nacional como estatal, de la época. En ellas se insistía en que los institutores públicos tenían plena autoridad sobre los niños en todo lo que se refiere a su educación, por lo que deben vigilar incesantemente su conducta ${ }^{6}$ no solo dentro de la escuela, sino también fuera de ella, para alcanzar un comportamiento acorde con los códigos morales y culturales de la cual era portadora la sociedad de su tiempo; dicho de otro modo, la sociedad era la que le predeterminaba al niño el comportamiento que debía asumir tanto en público como en privado. En general, las reglas eran transmitidas en la escuela a través de manuales de urbanidad y buenas maneras, con los cuales se buscaba transitar de una infancia bárbara a una niñez civilizada, que debía acatar en las escuelas una serie de deberes que de cierta forma definían la identidad del niño como alumno; por su parte, el alumno debía acatar una serie de deberes establecidos en los reglamentos de Instrucción Pública.

Cada una de las obligaciones resaltaba la necesidad de que el alumno se ajustara a los ritmos y tiempos de la escuela a través del establecimiento de horarios. Estos, además de periodizar las actividades educativas, buscaban regular los comportamientos de la infancia para que se ajustaran a los microsistemas de control y poder existentes en la escuela (Escolano, 2000, p. 85), los cuales pretendían ajustarse a las pautas temporales del sistema social y cultural de corte moderno que se buscaba imponer.

En ese proceso de construcción de la identidad del alumno y su disciplina, ${ }^{7}$ los reglamentos jugaron un papel importante en la medida en que a través de estos se divulgó la representación o la imagen deseada sobre este actor del escenario escolar y a quien se le consideraba un individuo obediente, bondadoso y cortés con todos, laborioso con sus tareas, respetuoso de la verdad y del buen uso del lenguaje. Así mismo, se insistía en que el alumno debía evitar hablar mal de las personas y no participar en los rumores que se generaban en las escuelas o fuera de ellas, para lo cual se le recomendaba alejarse de las malas compañías, procurando ser respetuoso de niñas y niños, al igual que inocente, puro, manso y humilde con sus maestros y compañeros; ser aseado y limpio con objetos personales y libros.

Después de todo, entre ese alumno soñado del cual se hace muy poca referencia en cuanto a sus responsabilidades de orden académico y el que realmente transitó por los espacios escolares, existen diferencias que muestran que estamos frente a un personaje más imaginado que real. Esto lo evidencian las descripciones que dan cuenta de niños y jóvenes que por las condiciones propias de su edad era normal que asumieran comportamientos que distaban mucho de lo exigido por los reglamentos. Por esta razón, era usual que al momento de las visitas los maestros se quejaran ante el inspector de escuelas:

[El maestro] luego se quejó de las molestias que frecuentemente le ocasionaban algunos de los alumnos por el poco orden que guardaban en la clase; lo que hacía que empleara un tiempo precioso en corregirlos y amonestarlos. (“Informe de Instrucción”, 1870). 
Quejas como la anterior eran muy comunes por parte de maestros y funcionarios escolares, quienes se mostraban molestos ante la tendencia general de "inobservancia [por parte de los alumnos] de las reglas de orden y disciplina establecidas en el decreto orgánico y en el reglamento interior de los establecimientos" ("Informe de Instrucción", 1873) y reclamaban que se les dotara de los medios para poderlas hacer efectivas:

Creo que se presenta la oportunidad de hacer en la organización del Colegio las reformas que la experiencia ha demostrado ser necesarias y de establecer además los medios de hacer efectivas las reglas que se juzgue conveniente fijar como base indispensable para la marcha ordenada de la educación. Hoy existen esas reglas, pero no están acompañadas de la sanción correspondiente para hacerlas efectivas. ("Informe de Instrucción”, 1871).

Este reclamo pretendía la ampliación de las sanciones a través de las cuales se castigaba a los alumnos que no acataran las reglas establecidas en la normatividad educativa. Ello fue utilizado como justificación para no suprimir totalmente los castigos de orden corporal, las reclusiones y el escarnio público, los cuales continuaron siendo justificados por quienes los consideraban necesarios para fortalecer el papel de la escuela en el proceso de disciplina de niños y jóvenes. A pesar de la implementación del método pestalozziano en las escuelas del país, los castigos mantuvieron su vigencia en el escenario escolar, buscando con ello la moralización de los sectores populares, quienes debían ajustarse a los cánones de la sociedad republicana, la cual a pesar de alcanzar importantes avances de orden cultural, educativo, económico, así como social y político a lo largo del siglo XIX, jamás renunció a justificar y aplicar las penas corporales como mecanismo para doblegar la voluntad del individuo, hasta el punto de que este aceptara, reconociera y corrigiera las faltas cometidas (Sáenz, Saldarriaga y Ospina, 1997, p. 205).

De esta manera, la escuela durante el periodo federal continuó asumiendo su rol de institución substancialmente disciplinaria, ${ }^{8}$ cuyo objetivo principal para el siglo XIX era la preservación, vigilancia y control de una población de niños circunscritos a un tiempo y espacio en particular y al cual debían habituarse. Para ello, debían acatar y cumplir con los reglamentos establecidos para las escuelas, que por muy insignificantes y alejadas que fueran debían hacerlos respetar por algunos alumnos:

Indómitos, pendencieros y díscolos, [en quienes, insistían los inspectores de vigilancia escolar, había que] fomentar... el amor al estudio, el respeto al orden, a la moral, a la ley y a las autoridades y a funcionarios públicos; haciéndoles conocer los funestos efectos de la desaplicación, de la inmoralidad, de la corrupción de las costumbres, y de la insubordinación a la ley y al Magistrado. (“Informe de Instrucción”, 1873, p. 12).

Se trataba de formar al ciudadano bajo los principios de una moral republicana que, a pesar de defender la libertad individual, no renunció totalmente al castigo como mecanismo de disciplina para moldear al niño-alumno, actor social considerado dúctil y dispuesto a ser corregido para que fuera capaz de asumir roles 
y comportamientos aceptados socialmente. La educación, a través de la institución escolar, sería la responsable, tal como lo afirma Botana (1994, p. 488), de configurar una sociedad impregnada de moral republicana impartida por los establecimientos públicos que debían forjar un ciudadano virtuoso, lo cual implicaba infundir disciplina y aquiescencia hacia el orden constitucional vigente. Esto se reflejaba para el caso que nos ocupa, en reglamentos, normas y métodos escolares a través de los cuales el maestro debía formar el carácter de los alumnos, de quienes simultáneamente había que erradicar una serie de vicios y reemplazarlos por virtudes republicanas con el propósito de forjar un individuo dispuesto a constituirse y comportarse como un ciudadano respetuoso y defensor de las leyes de la República. Para el caso colombiano se tropezaría con una serie de dificultades, pues para que este objetivo se pudiera lograr era necesaria la asistencia de los niños a la escuela y derrotar así uno de los más graves problemas de la instrucción pública: la inasistencia escolar.

\section{NOTAS}

$1 \quad$ Al respecto véase: "La historia de la educación en la actualidad: viejos y nuevos campos de estudio", p. 131, por A. Tiana, 2005, en Repensar la historia de la educación. Nuevos desafíos, nuevas propuestas, M. Ferraz (Ed.), España: Biblioteca Nueva.

2 Algunos trabajos que abordan la infancia desde la perspectiva histórica en los países latinoamericanos son: La infancia en los siglos XIX y XX. Discursos e imágenes, espacios y prácticas, A. Padilla, A. Soler, M. L. Arredondo y L. M. Moctezuma (Coord.), 2008, México: Casa Juan Pablos; Historia de la infancia en América Latina, p. 673, P. Rodríguez y M. E. Mannarelli, 2007, Colombia: Universidad Externado de Colombia.

Al respecto véase: "La infancia como sujeto y como objeto historiográfico", p. 102, por Á. Semeraro, en L. M. Moctezuma (Coord.), La infancia y la cultura escrita, México: Siglo XXI.

Sobre la región central del país, conocida también como el mundo andino colombiano, se destacan algunos trabajos que han permitido ampliar el conocimiento sobre las prácticas pedagógicas y la infancia, pero consideramos que aún no existe un trabajo que explore la infancia a lo largo de la historia nacional, en especial la que hace referencia a los dos primeros siglos de vida republicana. Entre los pocos estudios que sobresalen se encuentran: Mirar la infancia: pedagogía moral y modernidad en Colombia, 1903-1946, por J. Sáenz, Ó. Saldarriaga y A. Ospina, 1997, Colombia: Colciencias/Universidad de Antioquía; "La subordinación de la infancia como parámetro biopolítico y diferencia colonial en Colombia (1920-1968)", por J. C. Amador, 2009, Nómadas, (31), 240-256.

Ello resulta ser un caso atípico dentro del contexto latinoamericano cuya población creció vegetativamente a un ritmo del $1,1 \%$ durante el siglo XIX.

Al respecto véase el artículo 33 del Decreto Orgánico de Instrucción Pública, así como varios artículos del reglamento de las escuelas primarias del Estado del Magdalena, dictado el 7 de mayo de 1873 y firmado por Luis A. Robles, como director de Instrucción Pública. En: El Institutor, Santa Marta, 18 de mayo de 1873, No. 20. Aspectos también retomados en algunos 
manuales y publicaciones como la Guía de los Directores y Directoras de las Escuelas públicas del Estado de Cundinamarca.

7 Un enfoque novedoso sobre el papel disciplinar que juega la escuela en las sociedades liberales se encuentra en: "Del disciplinamiento a la indisciplina: Una lectura de la escuela desde la concepción foucaultiana de liberalismo", por J. C. Echeverri, 2009, Escritos, (38), 170-198.

Al respecto véase: “Los castigos en la Escuela ¿Cambios o continuidades?”, por E. De La Fuente y C. M. Recio, 2004, Revista Historia y Espacio, (19), recuperado de http://historiayespacio. univalle.edu.co/TEXTOS/19/Artículo4.pdf/

\section{REFERENCIAS}

Archivo Histórico del Magdalena. (27 de noviembre de 1871). Carta de Manuel Navarro al Director de instrucción pública. (Caja No. 15). Colombia: Archivo Histórico del Magdalena.

Archivo Histórico del Magdalena. (1872). Carta del maestro de escuela de Sitio Nuevo dirigida al Director de Instrucción Pública del Estado del Magdalena. (Caja No. 2). Colombia: Archivo Histórico del Magdalena.

Archivo Histórico del Magdalena. (1877). Correspondencia de los maestros de la Ciénaga dirigida al Presidente del Estado del Magdalena. (Caja No. 5, legajo 9). Colombia: Archivo Histórico del Magdalena.

Archivo Histórico del Magdalena. (1884). Cartas y quejas al Director de Instrucción Pública del Estado del Magdalena. (Caja No. 315). Colombia: Archivo Histórico del Magdalena.

Ariès, P. (1987). El niño y la vida familiar en el Antiguo Régimen. España: Taurus.

Becchi, E. (2005). La historia de la infancia y sus necesidades de teoría. En P. Davila y L. Naya (Eds.), La infancia en la historia: espacios y representaciones. España: Espacio Universitario.

Botana, N. (1994). Las transformaciones del credo constitucional. En A. Annino, L. Castro y F. X. Guerra (Ed.), De los imperios a las naciones: Iberoamérica, Caja de Ahorros y Monte de Piedad de Zaragoza (pp. 488). España: Ibercaja.

Brehony, K. J. (2009). Transforming theories of childhood and early childhood education: child study and the empirical assault on Froebelian rationalism. Paedagogica Histórica, 45(4-5), 585-604.

Carli, S. (2002). Niñez, pedagogía y política. Transformaciones de los discursos acerca de la infancia en la historia de la educación argentina entre 1880 y 1955. Argentina: Miño y Dávila.

Carrasquilla, R. (1866). Lo que va de ayer a hoy: cuadros de costumbres, 1866 (Sala 2A, 8957). Colombia: Biblioteca Nacional de Colombia.

Decreto Orgánico de Instrucción Pública. (1870). Colombia: Imprenta Nacional. 
Escolano, A. (2000). Tiempos y Espacios para la Escuela. Ensayos históricos. España: Biblioteca Nueva.

Flórez, C. E. y Romero, O. L. La Demografía en Colombia Siglo XIX. Recuperado de http://agora.edu. co/files/demografia-colombia-siglo-xix.pdf/

Foucault, M. (1996). Vigilar y castigar: nacimiento de la prisión. España: Siglo XXI.

Fröebel, F. (1885). La educación del hombre. Estados Unidos: Appleton.

Gosselman, C. A. (1981). Viaje por Colombia 1825-1826. Colombia: Banco de la República.

Guarin, R. (1876). Guía de los Directores y Directoras de las Escuelas Públicas del Estado de Cundinamarca. Colombia: Imprenta Gaitán.

Holton, I. (1981). La Nueva Granada: Veinte meses en los Andes (trabajo original publicado en 1857). Colombia: Banco de la República.

Informe anual del Gobernador de la provincia de Barranquilla. (28 de agosto de 1870). Gaceta de Bolívar (Archivo Histórico de Cartagena).

Informe de Instrucción Pública. Visita hecha al Colegio del Estado. (24 de julio de 1870). Gaceta de Bolívar (Archivo Histórico de Cartagena).

Informe de Instrucción Pública. Informe del Colegio del Estado. (3 de agosto de 1871). Gaceta de Bolívar (Archivo Histórico de Cartagena).

Informe de Instrucción Pública. Informe del Rector del Colegio del Estado. (26 de setiembre de 1873). Gaceta de Bolívar (Archivo Histórico de Cartagena).

Informe del director de la Instrucción Pública en el Estado del Magdalena. (29 de marzo de 1873). La Escuela Normal, (116-117), p. 95.

Informe del gobernador de la provincia de Magangué. (31 de agosto de 1881). Diario de Bolívar (Archivo Histórico de Cartagena).

Informe del señor Gobernador de la provincia del Carmen. (29 de julio de 1877). Diario de Bolívar (Archivo Histórico de Cartagena), p. 25.

Informe del director general de Instrucción Pública de Bolívar. (17 de agosto de 1878). Diario de Bolívar (Archivo Histórico de Cartagena).

Kalmanovitz, S. y López, E. (s.f.). El PIB de Colombia en el siglo XIX. Recuperado de http://ache.org. co/docs/ElPIBColombianoDuranteelSigloXIX2.pdf/

Leyes y Decretos del Estado del Magdalena 1857-1867/1868-1879. (1879). Colombia: Imprenta de Fonción Mantilla.

Melo, J. O. (2014). Historia de la población y ocupación del territorio colombiano. Recuperado de http://www.jorgeorlandomelo.com/histpobla.htm/ 
Mollien, G. T. (2004). El viaje de Gaspard-ThéodoreMollien por la República de Colombia en 1823. Colombia: Banco de la República.

Naradoswski, M. (1994). Infancia y poder. La conformación de la pedagogía moderna. Argentina: Aique.

Padilla, A. y Escalante, C. (2001). La infancia, la familia y la escuela en México a finales del siglo XIX. En L. Moctezuma (Ed.), La infancia y la cultura escrita (pp. 115). México: Siglo XXI.

Pancera, C. (2005). Complejidades y dificultades en la reconstrucción de imágenes y representaciones de la infancia en la historia social de la educación. En P. Davila y L. Naya (Eds.), La infancia en la historia: espacios y representaciones (pp. 21-38). España: Espacio Universitario.

Pérez, F. (1863). Jeografía física i política del Estado de Bolívar. Colombia: Imprenta Nacional. Recuperado de http://www.banrepcultural.org/blaavirtual/geografia/jeografia-fisica-i-politica-del-estado-de-bolivar/

Periódico Oficial de la Instrucción Pública. (6 de julio de 1872). Periódico Oficial de la Instrucción Pública, p. 214.

Posada, E. (1993). Entre las olas del Caribe: los recursos naturales durante el siglo XIX. En A. Meisel y E. Posada (Eds.), ¿Por qué se disipó el dinamismo industrial de Barranquilla? (pp. 93). Colombia: Gobernación del Atlántico.

Reglamento de la Instrucción Pública Primaria del Estado de Bolívar. (1886). Colombia: Archivo Histórico de Cartagena.

Revollo, P. M. (1998). Mis Memorias. Colombia: Editorial Mejoras.

Rodríguez, P. (2004). La familia en Colombia. En P. Rodríguez (Ed.), La Familia en Iberoamérica 15501980 (p. 268). Colombia: Universidad Externado de Colombia.

Sáenz, J., Saldarriaga, O. y Ospina, A. (1997). Mirar la infancia: pedagogía moral y modernidad en Colombia, 1903-1946 (tomo II). Colombia: Colciencias/Universidad de Antioquía. 